\title{
Clinical, respiratory, haemodynamic, and metabolic determinants of lactate in heart failure
}

\author{
Jan Biegus ${ }^{1,2}$, Robert Zymliński ${ }^{1,2}$, Mateusz Sokolski ${ }^{1,2}$, Piotr Gajewski ${ }^{1,2}$, \\ Waldemar Banasiak ${ }^{2}$, Piotr Ponikowski ${ }^{1,2}$ \\ 'Department of Heart Diseases, Wroclaw Medical University, Wroclaw, Poland \\ ${ }^{2}$ Centre for Heart Diseases, $4^{\text {th }}$ Military Hospital, Wroclaw, Poland
}

\begin{abstract}
A bstract
Background: Lactate is an end-product of anaerobic cell metabolism. Although it is believed to have prognostic significance in heart failure (HF), data on the pathomechanisms that lead to lactate accumulation are scarce.

Aim: We aimed to determine the clinical, respiratory, biochemical, and haemodynamic correlates of lactate in HF.

Methods: Patients diagnosed with HF hospitalised in a single cardiac centre, who underwent haemodynamic monitoring, were included in this retrospective analysis.

Results: The population consisted of 93 patients ( 44 acute HF [AHF] and 49 chronic HF [CHF] cases). The mean age, left ventricular ejection fraction, and lactate level were $60 \pm 13$ years, 33\% $\pm 17 \%, 1.4 \pm 0.9 \mathrm{mmol} / \mathrm{L}$, respectively. The mean cardiac index $(\mathrm{Cl})$, right atrial pressure (RAP) and pulmonary capillary wedge pressure (PCWP) were $2.2 \pm 0.5 \mathrm{~L} / \mathrm{min} / \mathrm{m}^{2}$, $8.7 \pm 6 \mathrm{mmHg}$, and $18 \pm 6 \mathrm{mmHg}$, respectively. AHF patients had significantly higher RAP, heart rate (HR), and levels of $\mathrm{N}$-terminal pro-B-type natriuretic peptide and creatinine, compared to the $\mathrm{CHF}$ group. Both $\mathrm{HR}$ and natriuretic peptide level were correlated with lactate. Among haemodynamic indices, lactate correlated with $\mathrm{Cl}(r=-0.25, p=0.01)$. We found no correlation between lactate and RAP $(p>0.05)$ or PCWP $(p>0.05)$. There was no relationship between lactate and peripheral blood gases. Lactate was strongly correlated with mixed venous oxygen saturation $\left(\mathrm{svO}_{2}\right)(r=-0.61, \mathrm{p}<0.05)$. $\mathrm{HR}, \mathrm{svO}$, and systemic vascular resistance (SVR) were found to be independent determinants of lactate.

Conclusions: Lactate accumulation in HF is not a result of respiratory disturbances or hypoxaemia. Among haemodynamic indices, $\mathrm{Cl}$ is correlated with lactate. The strongest determinants of lactate included $\mathrm{svO}_{2}, \mathrm{SVR}$, and $\mathrm{HR}$.
\end{abstract}

Key words: haemodynamics, heart failure, lactate, mixed venous oxygen saturation

Kardiol Pol 2019; 77, 1: 47-52

\section{INTRODUCTION}

Lactate is an end-product of anaerobic cell metabolism, which occurs during tissue hypoxia; therefore, it is a useful laboratory biomarker reflecting the severity of this phenomenon [1]. To date, lactate has been extensively studied in critical care medicine, and it is a well-established marker of poor outcome [2-4]. Data on the clinical significance and pathophysiology of lactate in heart failure (HF) remain scarce [5-7]. Recently, we demonstrated that elevated lactate level is common in acute HF patients (even without overt, clinical signs of hypoperfusion) and is related to organ dysfunction and higher mortality [7].
However, the exact mechanisms leading to hyperlactataemia in HF are still poorly explored. There are several potential pathways leading to accumulation of lactates in a failing heart: (i) insufficient supply of blood and oxygen to the peripheral tissues due to hypoxaemia leading to hypoxia, low cardiac output, vasoconstriction, impaired tissue perfusion (as a consequence of congestion and elevation of central venous pressure), or inability of the tissues to increase oxygen extraction; (ii) higher oxygen demand due to adrenergic drive and neurohormonal activation; and (iii) impaired lactate clearance — inability to eliminate the produced lactate. 
For better understanding of the pathophysiology of hyperlactataemia in HF, we attempted to investigate the respiratory, biochemical, and haemodynamic determinants of lactate in HF patients who underwent haemodynamic monitoring.

\section{METHODS}

\section{Study population}

We conducted a retrospective analysis of patients who were hospitalised in the Centre of Heart Diseases, $4^{\text {th }}$ Military Hospital, Wroclaw, Poland between March 2008 and December 2012 due to a primary diagnosis of HF, and who underwent haemodynamic monitoring with a Swan-Ganz catheter.

Exclusion criteria for the analysis were clinical and laboratory signs of infection, septic shock, known liver disease, and a diagnosis of acute coronary syndrome on admission. For the purpose of the present study, only patients with available lactate during catheterisation were included. Thus, 93 out of 158 patients who underwent haemodynamic monitoring in our institution composed the final study group. All patients underwent standard clinical evaluation and transthoracic echocardiography with the assessment of left ventricular ejection fraction (LVEF, Simpson's method) and end-diastolic dimensions of the left and right ventricles.

Patients were treated in accordance with the recommendations of the European Society of Cardiology [8]. The study protocol was approved by the local Ethics Committee (approvals number 282/2010 and 387/2015), and the study was conducted in accordance with the Helsinki Declaration.

\section{Laboratory measurements}

The following laboratory parameters were assessed in all patients using standard methods: blood counts (haemoglobin and platelets); renal function (creatinine and blood urea nitrogen); electrolytes (sodium and potassium); and plasma $\mathrm{N}$-terminal pro-B-type natriuretic peptide (NT-proBNP) levels (immunoenzymatic assay, Siemens, Marburg, Germany).

\section{Haemodynamic assessment}

An invasive assessment using a Swan-Ganz catheter was performed in patients referred for haemodynamic monitoring based on clinical evaluation. Indications for the procedure were as follows:

- clinical condition of patients with acute heart failure (AHF) - haemodynamic monitoring was a part of the standard cardiac intensive care in our institution;

- chronic heart failure (CHF) - haemodynamic assessment in heart transplant or cardiac surgery candidates;

- AHF/CHF patients - haemodynamic monitoring as a part of clinical trial procedures. If this was the case, all data used in this analysis were collected before randomisation or study intervention.

Haemodynamic variables obtained during catheterisation included heart rate $(\mathrm{HR})$, mean artery pressure (MAP), right atrial pressure (RAP), pulmonary artery pressure (PAP; systolic, diastolic, and mean), pulmonary capillary wedge pressure (PCWP), and cardiac output (CO; thermodilution method). Each invasive $\mathrm{CO}$ assessment included three to five separate injections of cold saline $(10 \mathrm{~mL})$ followed by $\mathrm{CO}$ calculation as a mean value of all injections. Cardiac index $(\mathrm{Cl})$ was determined as $\mathrm{CO}$ divided by the body surface area. Systemic vascular resistance and pulmonary vascular resistance were calculated using standard formulas: $80 \times(\mathrm{MAP}-\mathrm{RAP}) / \mathrm{CO}$ and $80 \times(\mathrm{PAP}-\mathrm{PCWP}) / \mathrm{CO}$, respectively. Systemic vascular resistance index and pulmonary vascular resistance index were computed by substituting $\mathrm{CO}$ with $\mathrm{Cl}$ in the respective formulas. Standard Swan-Ganz catheters (Edwards Lifesciences, Irvine, CA, USA) were used for monitoring.

Furthermore, blood samples from the right atrium and periphery were collected during the procedure for blood gas analysis, which included: $\mathrm{pH}$, oxygen saturation $\left(\mathrm{sO}_{2}\right)$ or mixed venous oxygen saturation $\left(\mathrm{svO}_{2}\right.$; in the case of assessment of right atrial blood samples), partial pressure of carbon dioxide $\left(\mathrm{pCO}_{2}\right)$, bicarbonate, and lactate (direct method, ABL 800 Flex analyser, Radiometer, Copenhagen, Denmark).

\section{Statistical analysis}

Continuous variables with normal distribution were described using means \pm standard deviation; variables with skewed distribution were described by medians with upper and lower quartiles; categorised variables were given as numbers and percentages. Statistical significance of differences between the groups was assessed using t test and Mann-Whitney $U$ test, where appropriate. The relationships between variables were assessed using Spearman rank coefficients. Multivariable regression analysis was performed to assess independent determinants of lactate. A p-value $<0.05$ was considered statistically significant. Statistical analyses were performed using Statistica 12 (StatSoft Poland, Krakow, Poland).

\section{RESULTS}

\section{Baseline characteristics}

Baseline characteristics of the study population are presented in Table 1. The study comprised 93 patients, among whom 44 (47\%) had AHF and 49 (53\%) had CHF. The participants were predominantly male (69 [74\%]). The most relevant concomitant diseases were coronary artery disease in 41 (44\%), hypertension in 30 (32\%), diabetes mellitus in 21 (22\%), and chronic obstructive pulmonary disease in eight (9\%) patients. The most common concomitant medications used were diuretics (82 [88\%]), angiotensin-converting enzyme inhibitor/angiotensin receptor blocker (70 [75\%]), $\beta$-blockers (72 [77\%]), and inotropes (14 [15\%]). Mean age, systolic blood pressure, haemoglobin, and serum creatinine level on admission were $59 \pm 13$ years, $110 \pm 19 \mathrm{mmHg}, 13.2 \pm 1.8 \mathrm{~g} / \mathrm{dL}$, and $1.1 \pm 0.4 \mathrm{mg} / \mathrm{dL}$, respectively. Mean lactate level and $\mathrm{svO}_{2}$ were $1.4 \pm 0.9 \mathrm{mmol} / \mathrm{L}$ and $58 \% \pm 12 \%$, respectively. The median (upper and lower quartiles) plasma concentration of NT-proBNP was $4313(2056 ; 7183) \mathrm{pg} / \mathrm{mL}$. 
Table 1. Baseline characteristics and comparison of patients with acute and chronic heart failure

\begin{tabular}{|c|c|c|c|c|}
\hline Variable & $\begin{array}{c}\text { All patients } \\
(n=93)\end{array}$ & $\begin{array}{c}\text { CHF } \\
(n=49)\end{array}$ & $\begin{array}{c}\text { AHF } \\
(n=44)\end{array}$ & $\mathbf{p}$ \\
\hline Heart failure aetiology: & & & & 0.005 \\
\hline Ischaemic & 41 & $13(32)$ & $28(68)$ & \\
\hline Valvular & 37 & $28(76)$ & $9(24)$ & \\
\hline Other & 15 & $8(53)$ & $7(47)$ & \\
\hline Age [years] & $60 \pm 13$ & $57 \pm 13$ & $62 \pm 12$ & 0.06 \\
\hline HR [bpm] & $75 \pm 15$ & $71 \pm 12$ & $79 \pm 18$ & 0.02 \\
\hline $\mathrm{SBP}[\mathrm{mmHg}]$ & $110 \pm 18$ & $113 \pm 16$ & $108 \pm 22$ & 0.24 \\
\hline LVEF [\%] & $33 \pm 17$ & $39 \pm 19$ & $26 \pm 10$ & $<0.001$ \\
\hline NT-proBNP [pg/mL] & $\begin{array}{c}4313 \\
{[2056 ; 7183]}\end{array}$ & $\begin{array}{c}2888 \\
{[1478 ; 5609]}\end{array}$ & $\begin{array}{c}5591 \\
{[3124 ; 9349]}\end{array}$ & $<0.001$ \\
\hline Sodium [mmol/L] & $139 \pm 4.2$ & $139 \pm 4.1$ & $139 \pm 4.5$ & 0.6 \\
\hline Potassium [mmol/L] & $4.2 \pm 0.5$ & $4.3 \pm 0.51$ & $4.0 \pm 0.4$ & 0.01 \\
\hline Creatinine [mg/dL] & $1.15 \pm 0.4$ & $0.97 \pm 0.2$ & $1.3 \pm 0.5$ & $<0.001$ \\
\hline Bilirubin $[\mu \mathrm{mol} / \mathrm{L}]$ & $26.5 \pm 16.2$ & $22.2 \pm 18.5$ & $29.1 \pm 11.8$ & 0.12 \\
\hline AST [IU/L] & $24[19 ; 35]$ & $25[21 ; 37]$ & $24[18 ; 34]$ & 0.37 \\
\hline ALT [IU/L] & $23[16 ; 36]$ & $25[18 ; 37]$ & $20[15 ; 34]$ & 0.12 \\
\hline Glucose [mmol/L] & $6.3 \pm 1.9$ & $5.9 \pm 1.3$ & $6.8 \pm 2.3$ & 0.053 \\
\hline $\mathrm{HGB}[\mathrm{g} / \mathrm{dL}]$ & $13.2 \pm 1.8$ & $13.6 \pm 1.5$ & $12.7 \pm 1.9$ & $<0.001$ \\
\hline Lactate $[\mathrm{mmol} / \mathrm{L}]$ & $1.4 \pm 0.9$ & $1.1 \pm 0.5$ & $1.7 \pm 1.1$ & $<0.001$ \\
\hline $\mathrm{sO}_{2}[\%]$ & $91.6 \pm 8.4$ & $91 \pm 9$ & $91 \pm 8$ & 0.94 \\
\hline $\mathrm{svO}_{2}[\%]$ & $58.2 \pm 12.0$ & $64 \pm 8$ & $51 \pm 12$ & $<0.001$ \\
\hline \multicolumn{5}{|c|}{ Haemodynamic parameters: } \\
\hline $\mathrm{CO}[\mathrm{L} / \mathrm{min}]$ & $4.1 \pm 1.0$ & $4.1 \pm 0.92$ & $4.0 \pm 1.1$ & 0.84 \\
\hline $\mathrm{Cl}\left[\mathrm{L} / \mathrm{min} / \mathrm{m}^{2}\right]$ & $2.2 \pm 0.5$ & $2.2 \pm 0.3$ & $2.2 \pm 0.6$ & 0.87 \\
\hline $\mathrm{MAP}[\mathrm{mmHg}]$ & $85 \pm 14$ & $88 \pm 12$ & $84 \pm 16$ & 0.11 \\
\hline PAP $[\mathrm{mmHg}]$ & $36 \pm 12$ & $35 \pm 10$ & $37 \pm 13$ & 0.35 \\
\hline $\mathrm{RAP}[\mathrm{mmHg}]$ & $8.7 \pm 6$ & $7 \pm 5$ & $11 \pm 6$ & 0.001 \\
\hline PCWP [mmHg] & $18 \pm 6$ & $17 \pm 6$ & $19 \pm 6$ & 0.19 \\
\hline SV [mL/beat] & $55.7 \pm 18$ & $58 \pm 17$ & $54 \pm 19$ & 0.24 \\
\hline SVR [dyn/s/cm] & $1578 \pm 456$ & $1652 \pm 458$ & $1492 \pm 442$ & 0.09 \\
\hline SVRI [dyn/s/cm] & $2957 \pm 729$ & $3077 \pm 649$ & $2824 \pm 795$ & 0.09 \\
\hline PVR [dyn/s/cm] & $368.7 \pm 226$ & $412 \pm 271$ & $319 \pm 146$ & 0.04 \\
\hline PVRI [dyn/s/cm] & $695.4 \pm 381$ & $754 \pm 450$ & $629 \pm 276$ & 0.11 \\
\hline LVSWI [g/m²/beat] & $28.1 \pm 11$ & $30 \pm 9$ & $26 \pm 13$ & 0.03 \\
\hline RVSWI [ $\mathrm{g} / \mathrm{m}^{2} /$ beat] & $11.1 \pm 5$ & $13 \pm 5$ & $9 \pm 5$ & 0.005 \\
\hline
\end{tabular}

Data are presented as number (percentage), mean \pm standard deviation, or median [lower and upper quartile]. AHF - acute heart failure; ALT — alanine aminotransferase; AST — aspartate aminotransferase; CHF — chronic heart failure; Cl — cardiac index; CO — cardiac output; HGB - haemoglobin; HR — heart rate; LVEF — left ventricular ejection fraction; LVSWI - left ventricular stroke work index; MAP — mean artery pressure; NT-proBNP — N-terminal pro-B-type natriuretic peptide; PAP — pulmonary artery pressure; PCWP — pulmonary capillary wedge pressure; PVR — pulmonary vascular resistance; PVRI — pulmonary vascular resistance index; RAP — right atrial pressure; RVSWI — right ventricular stroke work index; $\mathrm{SBP}$ - systolic blood pressure; $\mathrm{sO}_{2}$ — oxygen saturation; $\mathrm{SV}$ — stroke volume; $\mathrm{sVO}_{2}$ - mixed venous oxygen saturation; SVR — systemic vascular resistance; SVRI — systemic vascular resistance index

Conversion factors to SI units: for HGB $-10 \mathrm{~g} / \mathrm{L}$; for platelets -1 ; for creatinine $-88.4 \mu \mathrm{mol} / \mathrm{L}$; for NT-proBNP $-0.1182 \mathrm{pmol} / \mathrm{L}$ 
Table 2. Clinical and laboratory correlates of lactate

\begin{tabular}{|lcc|} 
Variable & $\mathbf{r}$ & $\mathbf{p}$ \\
\hline HR $[\mathrm{bpm}]$ & 0.32 & 0.02 \\
SBP $[\mathrm{mmHg}]$ & 0.07 & 0.62 \\
DBP $[\mathrm{mmHg}]$ & -0.12 & 0.34 \\
MAP $[\mathrm{mmHg}]$ & -0.11 & 0.27 \\
Creatinine $[\mathrm{mg} / \mathrm{dL}]$ & 0.13 & 0.31 \\
BUN $[\mathrm{mg} / \mathrm{dL}]$ & -0.12 & 0.37 \\
NT-proBNP $[\mathrm{pg} / \mathrm{mL}]$ & 0.28 & 0.03 \\
HGB $[\mathrm{g} / \mathrm{dL}]$ & 0.07 & 0.54 \\
WBC $[\mathrm{G} / \mathrm{L}]$ & 0.16 & 0.21 \\
Platelets $[\mathrm{G} / \mathrm{L}]$ & -0.11 & 0.39 \\
\hline
\end{tabular}

BUN — blood urea nitrogen; DBP — diastolic blood pressure; WBC — white blood cells; other abbreviations — see Table 1

Table 3. Haemodynamic correlates of lactate

\begin{tabular}{|lcc|} 
Variables & $\mathbf{r}$ & $\mathbf{p}$ \\
\hline CO $[\mathrm{L} / \mathrm{min}]$ & -0.20 & 0.055 \\
$\mathrm{Cl}\left[\mathrm{L} / \mathrm{min} / \mathrm{m}^{2}\right]$ & -0.25 & 0.014 \\
MAP $[\mathrm{mmHg}]$ & -0.11 & 0.27 \\
PAM $[\mathrm{mmHg}]$ & -0.17 & 0.09 \\
RAP $[\mathrm{mmHg}]$ & -0.06 & 0.54 \\
PCWP $[\mathrm{mmHg}]$ & -0.05 & 0.66 \\
SV $[\mathrm{mL} / \mathrm{beat}]$ & -0.32 & 0.002 \\
SVR $[\mathrm{dyn} / \mathrm{s} / \mathrm{cm}]$ & 0.12 & 0.24 \\
SVRI $[\mathrm{dyn} / \mathrm{s} / \mathrm{cm}]$ & 0.17 & 0.09 \\
PVR $[\mathrm{dyn} / \mathrm{s} / \mathrm{cm}]$ & -0.12 & 0.26 \\
PVRI $[\mathrm{dyn} / \mathrm{s} / \mathrm{cm}]$ & -0.11 & 0.29 \\
LVSWI $\left[\mathrm{g} / \mathrm{m}^{2} /\right.$ beat $]$ & -0.31 & 0.002 \\
RVSWI $\left[\mathrm{g} / \mathrm{m}^{2} /\right.$ beat] & -0.29 & 0.004 \\
\hline
\end{tabular}

Abbreviations — see Table 1

Table 4. Respiratory and metabolic correlates of lactate

\begin{tabular}{lcc} 
Variable & $\mathbf{r}$ & $\mathbf{p}$ \\
\hline $\mathrm{pH}$ & -0.33 & 0.007 \\
$\mathrm{pO}_{2}[\mathrm{mmHg}]$ & -0.14 & 0.26 \\
$\mathrm{pCO}_{2}[\mathrm{mmHg}]$ & 0.18 & 0.14 \\
$\mathrm{HCO}_{3}-[\mathrm{mmol} / \mathrm{L}]$ & -0.16 & 0.21 \\
$\mathrm{sO}_{2}[\%]$ & -0.01 & 0.97 \\
$\mathrm{svO}_{2}[\%]$ & -0.61 & $<0.0001$ \\
\hline
\end{tabular}

$\mathrm{HCO}_{3}{ }^{-}$- bicarbonate; $\mathrm{pCO}_{2}$ - partial pressure of carbon dioxide; $\mathrm{pO}_{2}$ - partial pressure of oxygen; $\mathrm{sO}_{2}$ - oxygen saturation; $\mathrm{svO}_{2}-$ mixed venous oxygen saturation

The mean $\mathrm{Cl}, \mathrm{RAP}$, and PCWP in the study group were $2.2 \pm 0.5 \mathrm{~L} / \mathrm{min} / \mathrm{m}^{2}, 9 \pm 6 \mathrm{mmHg}$, and $18 \pm 6 \mathrm{mmHg}$, respectively.

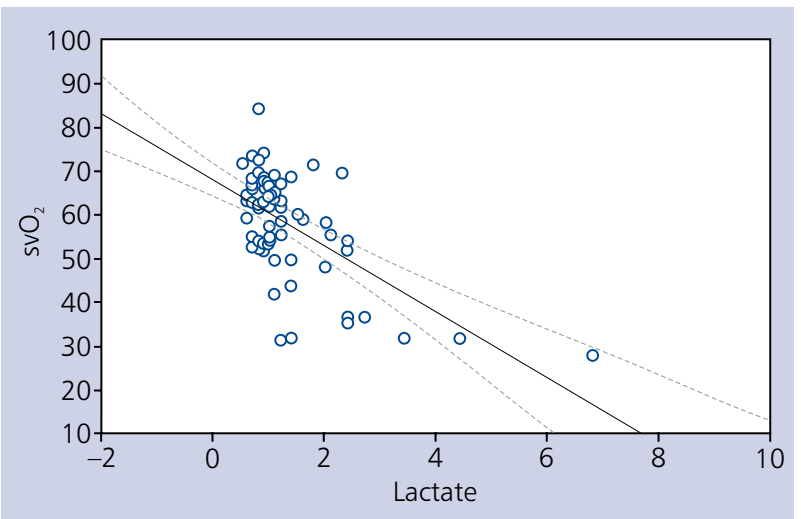

Figure 1. Correlation between lactate and mixed venous oxygen saturation $\left(\mathrm{svO}_{2}\right)$

\section{Comparison of AHF and CHF patients}

Patients with AHF had a significantly higher $\mathrm{HR}$ as well as NT-proBNP and creatinine levels compared to the CHF group (Table 1). Among haemodynamic indices, only elevated RAP differentiated AHF patients from those with CHF $(11 \pm 6 \mathrm{mmHg}$ vs. $7 \pm 5 \mathrm{mmHg}$, $\mathrm{p}<0.05)$. Moreover, patients with AHF had significantly higher mean lactate levels $(1.7 \pm 1.1 \mathrm{mmol} / \mathrm{L}$ vs. $1.1 \pm 0.5 \mathrm{mmol} / \mathrm{L}, \mathrm{p}<0.001)$ and lower $\mathrm{svO}_{2}(51 \% \pm 12 \%$ vs. $64 \% \pm 8 \%, \mathrm{p}<0.001)$ when compared to the CHF group (Table 1 ).

\section{Correlates of lactate}

Clinical, haemodynamic, and respiratory correlates of lactate are listed in Tables 2-4. Among clinical variables, only HR $(r=0.32, p<0.05)$ and NT-proBNP $(r=0.28, p<0.05)$ were significantly correlated with lactate. With regard to haemodynamic indices, lactate correlated with $\mathrm{Cl}(\mathrm{r}=-0.25$, $p=0.01$ ). We found no correlation between lactate and RAP, PCWP, or MAP (all $p>0.05$ ). There was no relationship between lactate and peripheral blood gases $\mathrm{pO}_{2}, \mathrm{pCO}_{2}$, or $\mathrm{SO}_{2}$ (all $\mathrm{p}>0.05$ ). In contrast, lactate was strongly correlated with $\mathrm{pH}$ and $\mathrm{svO}_{2}(\mathrm{r}=-0.4, \mathrm{p}<0.05$ and $\mathrm{r}=-0.61$, $\mathrm{p}<0.05$, respectively; Fig. 1 ).

\section{Determinants of lactate}

Multivariable analysis revealed that the strongest predictors of lactate were HR $(r=0.92, p<0.05), \mathrm{svO}_{2}(r=-1.18$, $p<0.05)$, and systemic vascular resistance $(r=0.52$, $\mathrm{p}<0.05$ ) (Table 5).

\section{DISCUSSION}

For the first time, we showed that patients with AHF have a significantly higher lactate concentration than individuals in a stable, chronic state. This is not surprising because each AHF episode seems to be an energetic challenge for the body; however, to the best of our knowledge, it has not yet been clearly shown. The mean lactate concentration in the 
Table 5. Determinants of lactate (multivariable analysis)

\begin{tabular}{|lcc|} 
Variable & $\beta$-coefficient & $\mathbf{p}$ \\
\hline $\mathrm{Cl}\left[\mathrm{L} / \mathrm{min} / \mathrm{m}^{2}\right]$ & 0.15 & 0.65 \\
$\mathrm{HR}[\mathrm{bpm}]$ & 0.92 & $<0.0005$ \\
NT-proBNP $[\mathrm{pg} / \mathrm{mL}]$ & 0.14 & 0.18 \\
Age [years] & 0.31 & 0.33 \\
$\mathrm{SVO}_{2}[\%]$ & -1.18 & $<0.0005$ \\
SVR $[\mathrm{dyn} / \mathrm{s} / \mathrm{cm}]$ & 0.52 & 0.02 \\
\hline
\end{tabular}

Abbreviations - see Tables 1 and 4

AHF group $(\sim 1.7 \mathrm{mmol} / \mathrm{L})$ was not as high as we expected, and approximately one-third of patients had lactate levels above $>2 \mathrm{mmol} / \mathrm{L}$. This is probably due to the fact that patients usually underwent Swan-Ganz catheterisation after initial treatment, which must have stabilised the patient and lowered the lactate level. However, this observation is in agreement with our previous report, in which we demonstrated that approximately $40 \%$ of AHF patients (without clinical signs of hypoperfusion) had elevated ( $>2 \mathrm{mmol} / \mathrm{L}$ ) lactate levels on admission [7].

There are several potential pathways that lead to lactate accumulation in AHF. We found moderate correlation of lactate with central haemodynamics. We also showed a relationship between lactate and $\mathrm{Cl}$ and systemic vascular resistance. Of note, there were no correlations between lactate and markers of congestion (such as RAP and PCWP). It should also be highlighted that we found no relationship between systolic, diastolic, mean arterial pressure, and lactate levels. This observation is in agreement with our previous report; this is not unexpected because blood pressure is not a simple surrogate of $\mathrm{CO}$ [7]. For example, patients with high systolic blood pressure and high systemic vascular resistance (such as patients with pulmonary oedema) may have elevated lactate levels. The finding that lactate correlated with central haemodynamics $(\mathrm{Cl})$ is not surprising, but we need to remember that its production is probably a result of depravation of blood flow on the microvascular level (microcirculation), beyond the scope of this study.

Secondly, we showed that lactate is not related to peripheral blood saturation in HF. This observation is of key importance because it shows that lactate accumulation is not a result of hypoxaemia and insufficient oxygen delivery to tissues. Therefore, the imbalance between the supply and demand is instead a result of insufficient tissue perfusion and increased tissue oxygen demand rather than low oxygen supply.

Most importantly, lactate is highly related to mixed venous oxygen saturation. The $\mathrm{svO}_{2}$ is a powerful marker reflecting tissue deoxygenation. Because it is measured in venous blood collected from the right atrium, it reveals the metabolic consequences of tissue perfusion and $\mathrm{CO}$. The $\mathrm{svO}_{2}$ is used in the Fick formula to estimate $\mathrm{CO}$ - the lower the $\mathrm{svO}_{2}$, the lower the CO. Generally, when microcirculatory blood flow is insufficient, the extraction of $\mathrm{O}_{2}$ increases, which leads to higher deoxygenation of the blood, and thus to lower $\mathrm{svO}_{2}$. The finding that the $\mathrm{svO}_{2}$ is the strongest, independent determinant of lactate is very important because it provides information not only about blood flow (perfusion) but also about its metabolic consequences.

Moreover, we revealed that lactate is strongly correlated with HR. This observation does not seem surprising because $\mathrm{HR}$ is associated with energy expenditure [9]. The relationship is obvious: the higher the HR, the higher the energy utilisation, which can lead to energy debt and lactate accumulation. This may also explain the fact that $\mathrm{HR}$ is a strong prognostic marker and a therapeutic goal in $\operatorname{HF}[8,10,11]$. Although there are several known markers of HF severity and outcome, lactate and $\mathrm{svO}_{2}$ seem to be distinct because they reflect the metabolic consequences of the disease [11, 12].

Finally, we noted that the correlates/determinants of lactate in the CHF group were weaker than in the AHF group (data not shown). This observation may simply be a result of significantly lower mean values of lactates in CHF patients and - even more importantly - the lower dispersion of lactate in this group.

We can conclude that lactate accumulation in HF is not a result of respiratory disturbances or hypoxaemia. Among haemodynamic indices, $\mathrm{Cl}$ is correlated with lactate. However, the strongest determinants of lactate are mixed venous oxygen saturation (a unique metabolic marker of tissue metabolism), $\mathrm{HR}$, and systemic vascular resistance.

Funding: The research was financed from a statutory grant for the Department of Heart Diseases, Wroclaw Medical University, Poland (ST-905) (to P.P.).

\section{Conflict of interest: none declared}

\section{References}

1. Andersen LW, Mackenhauer J, Roberts JC, et al. Etiology and therapeutic approach to elevated lactate levels. Mayo Clin Proc. 2013; 88(10): 1127-1140, doi: 10.1016/j.mayocp.2013.06.012, indexed in Pubmed: 24079682.

2. Nichol A, Bailey M, Egi M, et al. Dynamic lactate indices as predictors of outcome in critically ill patients. Crit Care. 2011; 15(5): R242, doi: 10.1186/cc10497, indexed in Pubmed: 22014216.

3. Meregalli A, Oliveira RP, Friedman G. Occult hypoperfusion is associated with increased mortality in hemodynamically stable, high-risk, surgical patients. Crit Care. 2004; 8(2): R60-R65, doi: 10.1186/cc2423, indexed in Pubmed: 15025779.

4. Kliegel A, Losert H, Sterz F, et al. Serial lactate determinations for prediction of outcome after cardiac arrest. Medicine (Baltimore). 2004; 83(5 274-279, indexed in Pubmed: 15342971.

5. Ander DS, Jaggi M, Rivers E, et al. Undetected cardiogenic shock in patients with congestive heart failure presenting to the emergency department. Am J Cardiol. 1998; 82(7): 888-891, indexed in Pubmed: 9781972.

6. Adamo L, Nassif ME, Novak E, et al. Prevalence of lactic acidaemia in patients with advanced heart failure and depressed 
cardiac output. Eur J Heart Fail. 2017; 19(8): 1027-1033, doi: 10.1002/ejhf.628, indexed in Pubmed: 27647751.

7. Zymliński R, Biegus J, Sokolski M, et al. Increased blood lactate is prevalent and identifies poor prognosis in patients with acute heart failure without overt peripheral hypoperfusion. Eur J Heart Fail. 2018; 20(6): 1011-1018, doi: 10.1002/ejhf.1156, indexed in Pubmed: 29431284.

8. Ponikowski P, Voors A, Anker S, et al. 2016 ESC Guidelines for the diagnosis and treatment of acute and chronic heart failure. The Task Force for the diagnosis and treatment of acute and chronic heart failure of the European Society of Cardiology (ESC). European Journal of Heart Failure. 2016; 18(8): 891-975, doi: 10.1002/ejhf.592.

9. Laurent D, Bolene-Williams C, Williams FL, et al. Effects of heart rate on coronary flow and cardiac oxygen consumption.
Am J Physiol. 1956; 185(2): 355-364, doi: 10.1152/ajplegacy.1956.185.2.355, indexed in Pubmed: 13327051.

10. Swedberg K, Komajda M, Böhm M, et al. Ivabradine and outcomes in chronic heart failure (SHIFT): a randomised placebo-controlled study. Lancet. 2010; 376(9744): 875-885, doi: 10.1016/S01406736(10)61198-1, indexed in Pubmed: 20801500.

11. Kapłon-Cieślicka A, Drożdż J, Filipiak KJ. Prognostic factors in heart failure - are they all equally important? Kardiol Pol. 2017; 75(6): 519-526, doi: 10.5603/KP.a2017.0088, indexed in Pubmed: 28553872.

12. Ostrowska M, Ostrowski A, Łuczak M, et al. Basic laboratory parameters as predictors of in-hospital death in patients with acute decompensated heart failure: data from a large single-centre cohort. Kardiol Pol. 2017; 75(2): 157-163, doi: 10.5603/KP.a2016.0147, indexed in Pubmed: 27714721.

Cite this article as: Biegus J, Zymliński, R, Sokolski M, et al. Clinical, respiratory, haemodynamic, and metabolic determinants of lactate in heart failure. Kardiol Pol. 2019; 77(1): 47-52, doi: 10.5603/KP.a2018.0240.

\section{WHAT IS NEW?}

Lactate is an end-product of anaerobic cell metabolism, which is detectable in heart failure (HF) patients. Although lactate is believed to have prognostic significance in $\mathrm{HF}$, data on the pathomechanisms that lead to its accumulation are scarce. Therefore, we attempted to analyse clinical, respiratory, biochemical, and haemodynamic determinants of lactate in HF patients who underwent haemodynamic monitoring with a Swan-Ganz catheter. We found that lactate accumulation in $\mathrm{HF}$ is not a result of respiratory disturbances. Among haemodynamic indices, cardiac index is correlated with lactate; no relationship was found between lactate and markers of congestion (such as right atrial pressure or pulmonary capillary wedge pressure). For the first time, we have demonstrated that the strongest determinants of lactate include mixed venous oxygen saturation, systemic vascular resistance, and heart rate. This finding is in line with our understanding of hyperlactataemia pathophysiology in HF, because all these variables are markers of energy utilisation. 